\title{
ESTABLISHING THE KEY ELEMENTS OF INCORPORATION AND OUTCOMES OF 4TH INDUSTRIAL REVOLUTION IN BUILT ENVIRONMENT EDUCATION: A MIXED BIBLIOGRAPHIC AND BIBLIOMETRIC ANALYSIS
}

\author{
Alireza MOGHAYEDI ${ }^{1}$, Karen LE JEUNE ${ }^{2}$, Mark MASSYN ${ }^{2}$ and Christiana \\ Okobi EKPO ${ }^{4}$
}

1,2,3\&4 Department of Construction Economics and Management, University of Cape Town, Cape Town, South Africa, 7700

Email: Alireza.moghayedi@uct.ac.za'1; Karen.lejeune@uct.ac.zaª; Mark.massyn@uct.ac.za ; Christiana.ekpo@alumni.uct.ac.za ${ }^{4}$

\begin{abstract}
The rapid, exponential fusion of technologies which profoundly disrupts all industries and processes is commonly described as the Fourth Industrial Revolution (4th IR). The Built Environment (BE) sector has long been overdue for radical transformation that is symphonious with global trends. Consequently, how to incorporate 4th IR in BE education remains challenging. This research aims to establish what educational methods, context, tools, and technological pedagogy are required and should be adopted, as well as what the effects and outcomes can be expected from the incorporation of the 4th IR concepts in BE education. The rationale for this research stems from the aspiration to meet the United Nation Sustainable Development Goals, which advocate that young people need to be "future-ready" and this includes digital fluency and ICT literacy. The study utilised a verifiable and reproducible systematic literature review of digital education; with analysis and scrutiny of 582 academic articles for the co-occurrence of keywords, using a mixed bibliographic and bibliometric method. Through clustering analysis based on the bibliometric method, the key elements, outcomes, and their interconnections of incorporating 4th IR in BE education were outlined. The paper revealed that, in adopting 4th IR, Higher education, Design, Innovation and Privacy appear to be the predominant context. Distance education, Collaborative learning and Digital learning are the foremost education methods. Digital technologies, Virtual reality and cloud computing are the most significant education tools and technology elements. Sustainable education, Ethical learning and Student engagement are the resultant primary outcomes of incorporating 4th IR in built environment education. In addition, the results of the interconnections of indicators analysis revealed Higher education, Distance education and Sustainable education are significantly intertwined with Digital technologies. Based on the taxonomy of key elements and outcomes and the analysis of their interconnections, a conceptual framework for adopting 4th IR in built environment education was developed.
\end{abstract}

Keywords: 4th Industrial revolution, Built Environment, Education, Key elements, Outcomes

\section{INTRODUCTION}

The Built Environment (BE) collectively describes products and processes of human creation (Mazumdar et al., 2018), and the environments with which people interact most directly, are often the products of human-initiated processes (Haig \& Amaratunga, 2010). There has been 
a rapid evolution in new technologies and project delivery methods in recent years, to address the inefficiencies that exist in the BE and the 4th Industrial Revolution (IR) and digitalised innovative technology have contributed significantly (Solnosky \& Parfitt 2015). The implementation of 4th IR in the BE industry is meant to advance mechanized automation technological interconnectedness with operation and communication that encourages less humans' involvement and further improves efficiency, saves time, and improves product quality (Alaloul et al, 2020). Walden, (2017) agrees that the advent of technology has increased in the rate of changes in the $\mathrm{BE}$ and plays an essential role in deciding the way forward for the industry. Unfortunately, even when technology progressively acts as a catalyst for change, the global BE industry is responding to it very slowly and is known for its poor track record in driving change (Whyte 2017). The BE industry has over time been on the slower end of adopting these new technologies (Whyte 2017). The BE industry shows hesitation in implementing these 4th IR concepts despite the numerous benefits it proffers in other industries (Alaloul et al, 2020). In order for the present and future generation to create and maintain pertinent labour forces there needs to be some modifications and convergence, then new techniques, awareness and expertise are required (Zabidin et al., 2019) to be able to compete in industry transformation, and the global industrial revolutionary vision. There is, therefore, a need for an education framework and a research base that supports the industry in digital technological transformation for both immediate and future learning for the integration of digital and innovation strategies (Whyte 2017).

Unlike other industries, no breakthrough on rudimental productivity has been achieved as most BE projects today operate almost identically as several decades ago (Foroughi Sabzevar et al., 2020). This is confirmed in results from many studies where the findings have shown similar challenges of systems inefficiencies, delays in construction, cost and time overruns that generally affect productivity. However, a profound shift is being observed in the role that automation and skills acquisition play in promoting improved productivity and economic progress, leading to the application of the term "industrial revolution" which is seen as the occurrence when changes in social, economic and technological industrial systems are driven by progressively advanced intelligent-scientific solutions (Dombrowski \& Wagner, 2014). Parn and Edwards (2019) describes digital knowledge as both the engine and product of economic growth which the engineering and built environment industry apparently contributes to. Kozma, (2003) believes that the creation, distribution and application of new information and skills can contribute significantly to increased productivity and create very lucrative job opportunities as well. Bates (2016) also acknowledges that contemporary society appear to be technologically engrossed in the 4th IR concepts and consumed by the hype in a way that shows no sign of declining judging by the ready acceptance of the rapid rate of change and the fact that most knowledge-based activities depend heavily on their usage by society at large. However, Bates (2016) argues that educational institutions are largely not predisposed towards the current digital era even though uptake in technology is leading to massive changes in economies, communication, relationships and learning processes.

The more technological development increases and these trends progressively gain more momentum, practitioners and academia have realised that education on these topics is essential and in order to adopt these concepts, proper and well-tested courses and curriculum restructuring are required (Solnosky \& Parfitt 2015). For this trend to particularly change in most parts of the world, Jacobs (2015) opines that higher education, as the bedrock for achieving most knowledge and skills, should be given corresponding attention to ensure that the sustainable digitalised technologies' principles and concepts that meant to enhance knowledge, are embedded within the knowledge domain to further foster industrial transformation and enhance efficiency and productivity.

No concrete framework has been adopted to fill this gap in the literature. Therefore, this study, aims to identify the key elements of the 4th IR in BE education and develop a 
framework to assess the incorporation and impact of digitalised innovative technology in Engineering and built environment education. In an attempt to facilitate better integration of 4th IR and digitalised innovative technology into the built environment education, this study explores the current applications of 4th IR in education of the Built Environment through a mixed bibliographic and bibliometric analysis. The objective of this study is firstly to identify the current status of 4th IR and education adaptation through critical literature review. Secondly, this study further examines the application of 4th IR and outcomes as obtained from reviewed literature. Finally, the study develops a conceptual framework for adopting 4th IR to the built environment education by identified the key elements of incorporating 4th IR in built environment education and its outcomes.

\section{LITERATURE REVIEW}

Higher educational institutions have been acknowledged for the significant role they play in providing the BE industry with innovatively well-equipped graduates (Jin et al., 2015). However, insufficiency still exists in most institutional education resources, and this poses a huge challenge to train the built environment students in order to meet industry needs in most parts of the world, where the industrial demand for professionals proficient at understanding innovative concepts is growing (Jin, et al. 2018; Jacobs, 2015). Consequently, developing the kinds of graduates from existing courses and programs that fit into the increasingly complex, ambiguous, volatile and uncertain future are required in the direction that can enable them to compete favourably in the BE market (Bates 2016).

Tertiary institutions are therefore obliged to respond to digitalised technology demands to equip students with 4th IR skills and competencies for the labour markets, thus requiring changes in the BE education (Bai et al., 2020; Philips 2017; Bates, 2016; Jacobs 2015). Inefficiencies that manifests in delays in planning, building and construction processes that cause cost and schedule overruns and further impact on efficiency and productivity in the BE industry are gradually being addressed, and the 4th IR education is being propagated as a partial way out. The 4th IR tools promise to reshape construction around the world and redefine projects' lifecycle, drive productivity and efficiency for better outputs (Philips 2017; Foroughi Sabzevar et al., 2020). Bates (2016) suggests that the overall level of knowledge in 4th IR concepts are not adequate, that significant knowledge gaps exist and that there is a lack of relevant training to bridge the divide in digital innovative technological education.

\subsection{Effects of 4th IR on Education}

The current trends in 4th IR are gaining more traction in education partly due to the way in which these trends impact education. Newman, (2017) argued that educators in most of the developed world have realised that lecture rooms are now made to simulate the workplace, and to encourage and create collaborative-friendly spaces that facilitate student learning. In comparison, a typical classroom across most parts of the developing world still comprises rows of desks, all pointing toward the front of the classroom or studio. The evolution from chalkboards to 21 st-century smart boards in lecture rooms and smart desks in pod formation rather than individual seating ameliorates the transformation in educational technology (Newman, 2017). Han (2020) agrees that students are embarking on virtual field trips rather than merely just studying from books and are actively involved in creating educational media rather than just being ordinary spectators. The redesigned learning spaces are designed with integrated technology, which means students are not just using these facilities, but are engaging with the facilities and understanding how to apply and use the armamentarium in order to achieve targeted goals set primarily for the workplace.

Smith and $\mathrm{Hu}$ (2013) argue that the important skills needed for 4th IR such as systems thinking, computational literacy, creativity, empathy, and abstract reasoning, are difficult to 
teach, and therefore digitalised teaching tools such as Virtual reality (VR), which is an immersive, hands-on tool for learning among other tools, can play a unique role in addressing such BE educational challenges. Other tools such as Artificial Intelligence (AI) and Machine Learning, Computer-aided design (CAD), Computer-aided manufacture (CAM), Building Information Modelling (BIM), 3D-printing, Cloud-based computing and mobile applications are useful in the way these tools are not only improving teaching and learning pedagogy but the BE workforce too. The adoption of BIM, for instance, aids the incorporation of processes throughout the whole lifecycle of a construction project. BIM focuses on consistently creating and reusing digital information from all stakeholders in a project's lifecycle. It is useful in urban development planning and design as well as for enhancing safety, code checking, general construction, and many other benefits (Kamaruzaman et al., 2019). The BE industry is going through 4th IR paradigm shift in order to firstly improve; efficiency, productivity, quality, sustainability, and infrastructure value, and secondly reduce; lead times and lifecycle costs, via effective communication and collaboration of stakeholders in built environment projects (Bates, 2016).

A virtual world, for instance, offers the opportunity to create a virtual reality, which is typically a multi-user, computer-based environment in which users interact with one another through pre-programmed avatars or digital representations of the user (Philips 2017). It allows educators to have virtual excursions; take students to otherwise infeasible sites (Dunleavy \& Dede, 2014). Science, medicine and maths departments in most institutions have particularly incorporated virtual environments but the adoption of VR is uncommon to the $\mathrm{BE}$ as yet. The successful application of VR in simulating medical procedures is adequately documented, because it permits errors and mistakes to be made with no adverse consequences to real-life patients. VR can be applied in the BE industry to avert construction disasters too. Through 4th IR education, engineering and BE disciplines are able to engage with real-life issues through virtual reality, for instance real estate students who can learn how to apply Geographical Information Systems (GIS) when identifying sales trends and prices in various geographical localities (Windapo \& Moghayedi, 2019); Surveyors can use drones to access the topography and features on a site without necessarily being on-site; Architecture students can view the interior of their designs in the virtual world and make amendments to spaces and building components which appear not to be functional thus averting potential fatalities; mechanical engineers are be able to use robots to unblock blocked pipes and engineers can generally employ the use of digital technologies to simulate the construction and functioning of structures to understand how effective and applicable their ideas are in real-life (Moghayedi, 2019).

Historically, infrastructure projects have relied on 2D design and CAD work, and a large percentage of projects are still represented with $2 \mathrm{D}$ digital drawings. More recently, however, technology is being designed and utilised specifically for educational contexts, and it is changing the way students learn and understand things (Shvets \& Nedviga, 2019). Cloud computing advancement in combination with mobile and social media are giving rise to costeffective, concomitant and actual information being available; the application thereof in the property industry implies that some online leasing activities are taking place too. The latest technology to launch into the educational landscape is Augmented Reality (AR) which allows for digitised information to be overlaid on actual-world objects through mobile device camera like tablet or smartphone. In converse to virtual reality, where the real world is obscured, and the user is immersed in a fully digital yet life-like experience (Philips, 2017). In some educational uses of AR, the three-dimensional images, text, video or audio are induced to appear by a printed image.

Phillips' (2017) research has shown that although innovative digital technology enhanced self-directed learning, there are still technological and pedagogical challenges such as slow response times, incompatible software and conflicting environmental settings that need to be overcome. An industrial revolution is known to shape work circumstances, life 
conditions and economic wealth. Skills development is a major area that is impacted and influenced, and thus is regarded as the most important key factor for the successful adoption and implementation of 4th IR (Periera \& Romero, 2017). Khan and Khan (2018) assert that technology permeates the societal fibre of modern life and forms the basis for automatic data processing, telecommunications, photography and navigation, as well as manufacturing and finance. Innovation on the other hand "is an idea, practice or object that is perceived as new by an individual or the unit adopting it" (Khan \& Khan, 2018). Philip (2017) espouses that a societal shift has occurred caused by digital automations in the BE industry, which embodies a set of tools that utilise and control digital data to enhance, deliver and operate the construction and built environment. In considering AR, VR and Mixed Reality (MR), for instance, Newman, (2017) argues that these are exemplary examples of transformative technology that can help to improve teacher instruction while concurrently creating enticing lessons that engage students as it makes learning exciting, collaborative, interactive and fun.

VR, for instance, has been able to connect the outside world with the classroom and vice versa and has the capability to enhance technological and visual literacy as well as hold the attention of the audience for longer, which when all three are achieved, results in beneficial learning (Schrock, 2014; Newman, 2017). The digital technology devices used in 4th IR education have undoubtedly improved collaboration and knowledge transferral within the educational domain as well as the building team and stakeholders in the BE industry (Desjardins \& Bullock, 2019). Research is also beginning to provide propitious illustrations of how, when and where the 4th IR technologies may conform to the pedagogical collection of educators (Newman, 2017). Therefore, not only are students more motivated, but collaboration is improved, and knowledge construction is promoted through enhanced classroom study practices which engage with all these devices (Dunleavy \& Dede, 2014).

\subsection{Challenges of 4th IR Incorporation in Built Environment Education}

Educators in most parts of the world face major challenges as a result of the paradigm shift to 4th IR era (Wadhera, 2016). They are challenged with the mammoth task of finding contemporary approaches that enhance learning experiences and academic performance of current and future students. Experiential teaching and learning that involve multisensory activities require educators to embrace and leverage better teaching delivery methods that allow for the most effective learning experiences (Hernandez-de-Menendez \& MoralesMenendez, 2019). Digital technological teaching devices and methods offer wide application of learning possibilities for improved education. This has caused an increasing interest among the BE authorities and educators to integrate 4th IR innovative technologies and concepts into degree programmes (Abdirad \& Dossick 2016). Much is known about the current strategies that degree programmes aspire to and the instructors implement in their curricula, as well as the challenges they faced, and the educational outcomes envisaged by $\mathrm{BE}$ disciplines. However, so far, no study has critically combined existing knowledge and findings with the implications of 4th IR in BE education (ibid). In response to the 4th IR disruption, the BE industry and academia around the world should realise that embedding 4th IR knowledge and skills, principles and concepts through innovative education pedagogies in university curricula is an important requirement to satisfy educational demands of the contemporary BE industry. This is because many challenging constraints exist that hinder resources acquisition thus promoting systems' inefficiencies and unproductivity in the BE industry thus increasing the need for effective and sustainable architecture, construction and project management solutions amidst urban pressures (Clevenger et al., 2017). The increasing inadequacy in knowledge and skill acquisition of 4th IR and innovative digitalised concepts among most lecturers and students alike directly reflects in the inefficient, imprudent execution and implementation of projects - by modern standards - in the BE industry (Jacobs 2015). These inadequacies are attributed to a lack in corresponding, relevant education that is needed to unlock the potential in BE professionals 
via education, and seen as a major barrier to progress (Bai et al., 2020; Bates, 2016; Jacobs; 2015; Shafii, Ali \& Othman, 2006). Designers, Construction engineers and property developers often make decisions that impact on the environment and society (Clevenger et al., 2017) and ability to make well-informed, holistically viable contributions depends on the type of acquired knowledge that informs them. Hwang (2019) expresses concern about ignoramuses seeking ways to proffer sustainable solutions on how to adopt technologies that strive for efficiency and optimisation that can improve, low levels of productivity, efficient and cost-effective work methods.

Schilling and Shankar (2019) argue that technologies, which were initially reserved only for very expensive industries like the oil and gas and aerospace sectors, are presently becoming more accessible and affordable to a much broader range of professionals as the technology prices decrease. The BE education sector needs to take advantage of this. It is, however, noted that $\mathrm{BE}$ education, unfortunately, is one of the last industries to make an extensive change, holding on to the classical methods and practices (Philips, 2017). Nevertheless, the 4th IR and digital transformation are helping to change the tide through technology education, and educators have begun making drastic changes to their pedagogy, assessments methods, even the physical architecture of their classrooms (ibid).

\subsection{Key Elements 4th IR Conceptual Framework}

In very broad terms, 'digital' refers to data or signals that are expressed by the digits 0 and 1. Digital technology describes networks, structures, tools and operations and processes that utilise digital data or signals to attain a specific user-defined results. Digital technology unveils economic and social opportunities revealed in the paradigm shift experienced in labour structures, business models and production technology due to the 4th IR. (Windapo \& Moghayedi, 2020). The 4th IR or Industry 4.0, according to Periera and Romero, (2017) is an automated system that effectuates the latest developments that align with future smart technology. It connects the physical and digital worlds through the Cyber-Physical Systems (CPS) technology, sparking future industrial advancements that create improved efficiency and productivity among companies that are oriented towards the paradigm change (Schmidt et al., 2015). What then is 4th IR education all about and what are the key elements that need to be incorporated in BE education and what will be the outcomes - these are the questions that this study seeks to answer.

Bates (2016), reveals that knowledge includes two cogently fused but different constituents, namely "content" and "skills". Content involves principles, facts, evidence, ideas, and descriptions of processes or procedures, and skills, on the other hand, involves efficiency, experience, abilities, prowess, and ingenuity in what one is doing. How much of these do university education offer? Bates (2016) agrees that most University instructors are correctly equipped with knowledge and well-grounded in content and have a deep comprehension of the subject areas they teach. Neither is the problem the educators' ability to help students develop skills and talents, but rather, the concern lies with contemporaneity of their intellectual expertise to match the needs of knowledge-based workers, and whether enough emphasis is paid to skills development within BE education (Bates 2016). Thus, educators and instructors are faced with a massive but vital challenge to incorporate the ideals of the 4th IR and digital technologies in BE educational systems in most parts of the world in order to enhance knowledge and transform the construction and BE.

Educational institutions have to consider the transformation of the approaches in the way they work and teach in order to fit in with 4th IR (Newman, 2017). OECD 2018's report on 'Future of Education and Skills 2030: Conceptual Learning Framework' concludes that; digital literacy is now a fundamental learning objective, which includes information handling skills, and the capacity to judge its relevance and reliability, and the switch to open, skillsbased, student-centred approaches in the education system supported by ICT will ensure the 
4th IR is inculcated in schooling, teaching and learning across the board (Taguma et al., 2018).

\section{RESEARCH METHODOLOGY}

\subsection{1 Keywords, Databases, and Inclusion Criteria}

This section aims to elucidate the methodological approach that forms the basis of this study. It is fundamental to have an indication of the main characteristics that define this research, prior to defining and applying any research method, to which end, Figure 1 illustrates the adopted methodological framework applied to this bibliometric research. The main goal of the study is to identify the key elements of 4th IR that need to be incorporated in BE education and what the expected outcomes should be. By developing a comprehensive bibliographical control structure, it has been understood that the potential results achieved through this method has the capacity to address all the concerns raised in this study. The bibliometric research approach of this research comprises four phases, and embodies; the establishment of a keyword database, ascertainment of the bibliographic database to include in the study, conducting the document search and finally, analysing the resultant literature sample. The desktop data collection was conducted during the month of June 2020.

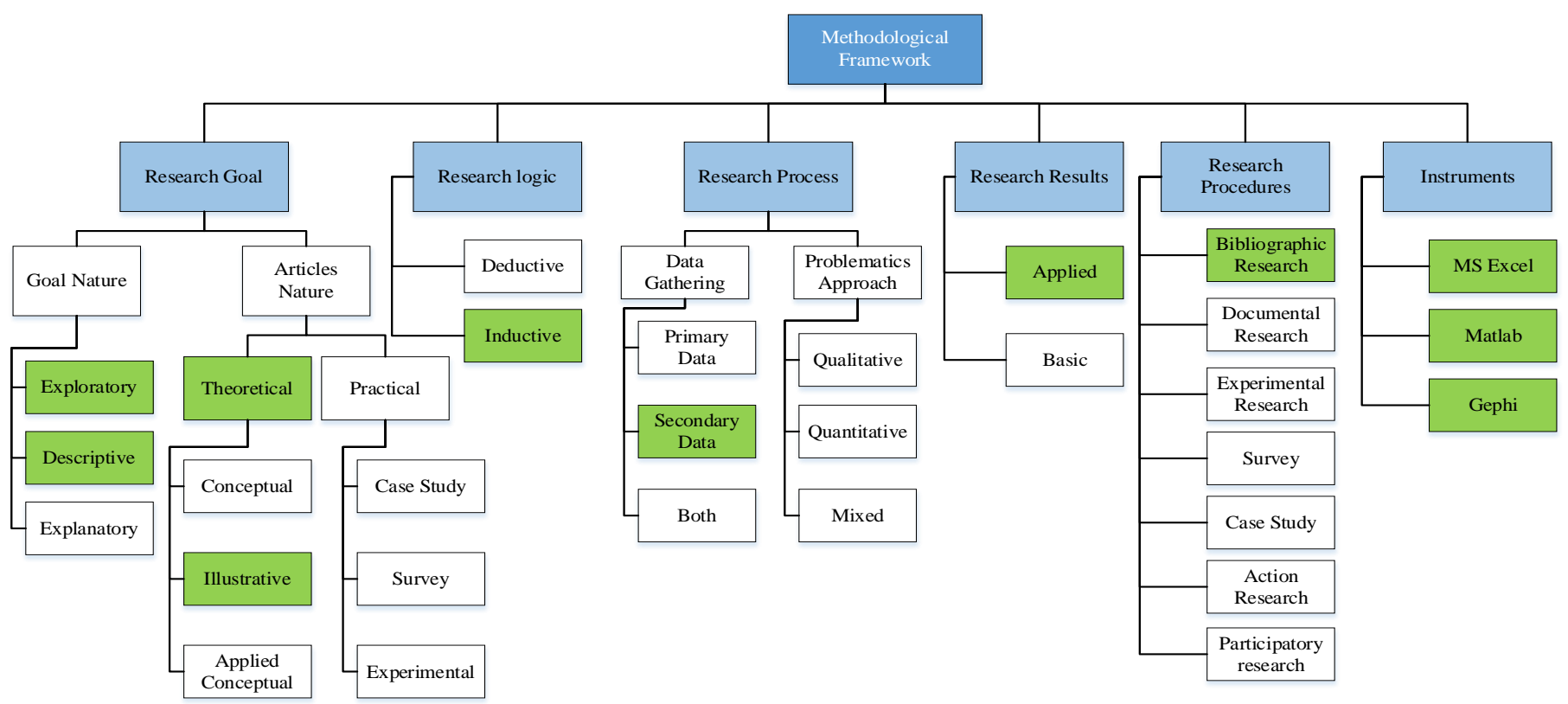

Figure 1. Adopted methodological framework

\subsection{Keyword Database Establishment and Bibliographic Database Selection}

The initial step in the bibliometric analysis was the establish a keyword database which would be applied in the bibliographic databases. This enabled the researchers to find publications potentially related to the themes under study. Reflecting on this, the authors determined that the following keywords would be used, namely, Digital Technology/Technologies, Education, and Built Environment. The study considered document titles, abstracts and author keywords. Two major bibliographic databases, namely Scopus and Web of Science, were used to search for pertinent documents, thus ensuring that the majority of all relevant publications would be included in the keyword search. Together, the keyword database establishment phase and the bibliographic database selection phase of the research, demarcate the boundaries of the study, considering that the resultant portfolio 
of publications compiled after the document search is conducted, could be viewed as the definitive reference list for the topics under study.

\subsection{Document Search}

bibliometric study further considered specific parameters, namely subject topic and document types. The results were limited to the Computer Science, Education science, Social Science, Environmental and Engineering subjects, and although the documents in the research results were limited to the Final peer-review conference processing and journal articles published in English only, there was no restriction on the date of publication of the documents. As the next step, it was feasible to combine the results from the two databases (Scopus 301 documents and Web of Science 427 documents). After re-evaluating the alignment of the titles and keywords of the resultant 728 documents to the research theme, 146 articles were excluded, leaving the authors with a portfolio of 582 relevant articles.

\section{DATA ANALYSIS}

The following criteria were used to analyse the publications' portfolio:

- Trend of publications over time

- Publication "Country of Origin" analysis

- Keyword analysis

- Keyword clustering analysis

- Interconnection analysis

\subsection{Trend of Publications Over Time}

Figure 2 shows the publication trend of the documents on digital technologies in BE education. Although the publication time span criteria had been unlimited, only four relevant documents were published before 2000 , which renders digital education as a relatively recent and novel research field. The increasing publication trend has been quite stable in the whole period of study. Moreover, $57 \%$ of the resultant sample of documents were published in the last five years. This large number of documents could possibly be attributed to the increased attention around the 4th IR, which has encouraged scholars to engage more significantly with research on digital education in $\mathrm{BE}$.

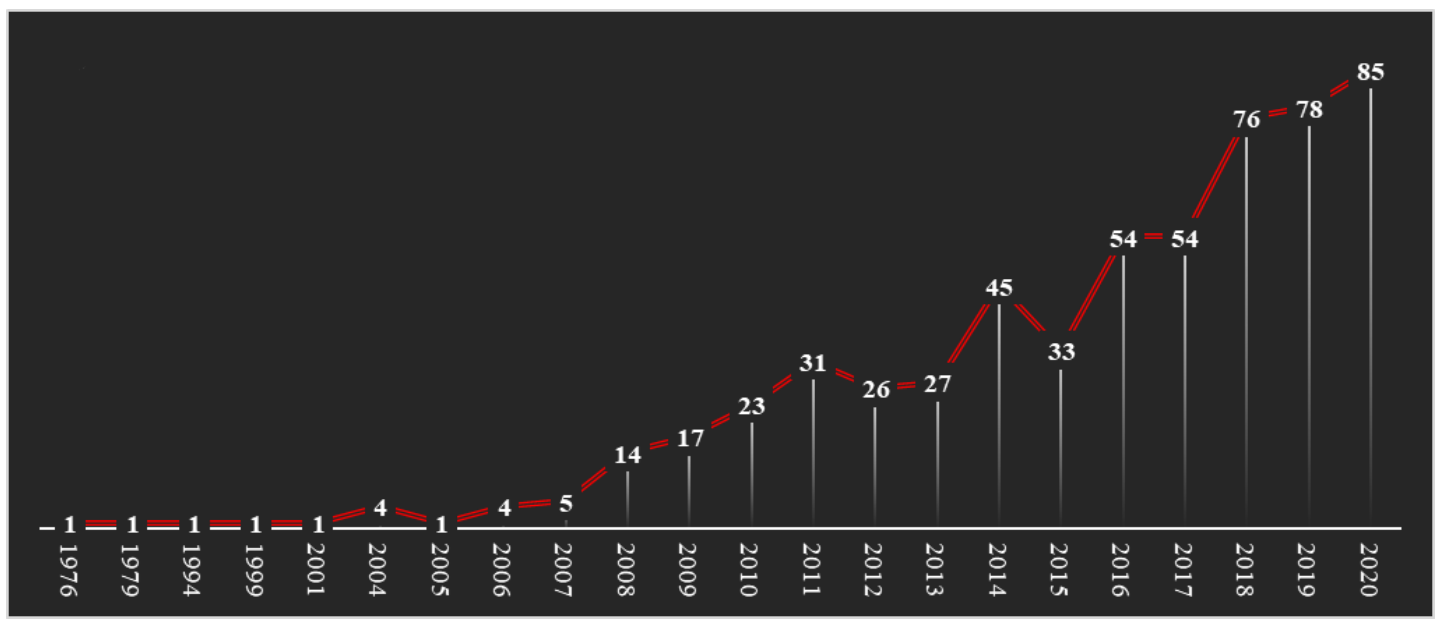

Figure 2. Publication trend 


\subsection{Publication "Country of Origin"}

The number of document publications per region and per country is viewed as an indication of the regions and countries that are taking an interest in this specific topic. Thus, it is deemed meaningful to analyse the various countries' contributions to obtain a sense of the current 4th IR practices in the BE education. Figure 3 shows the region and countries of origin of publications according to the number of publications.

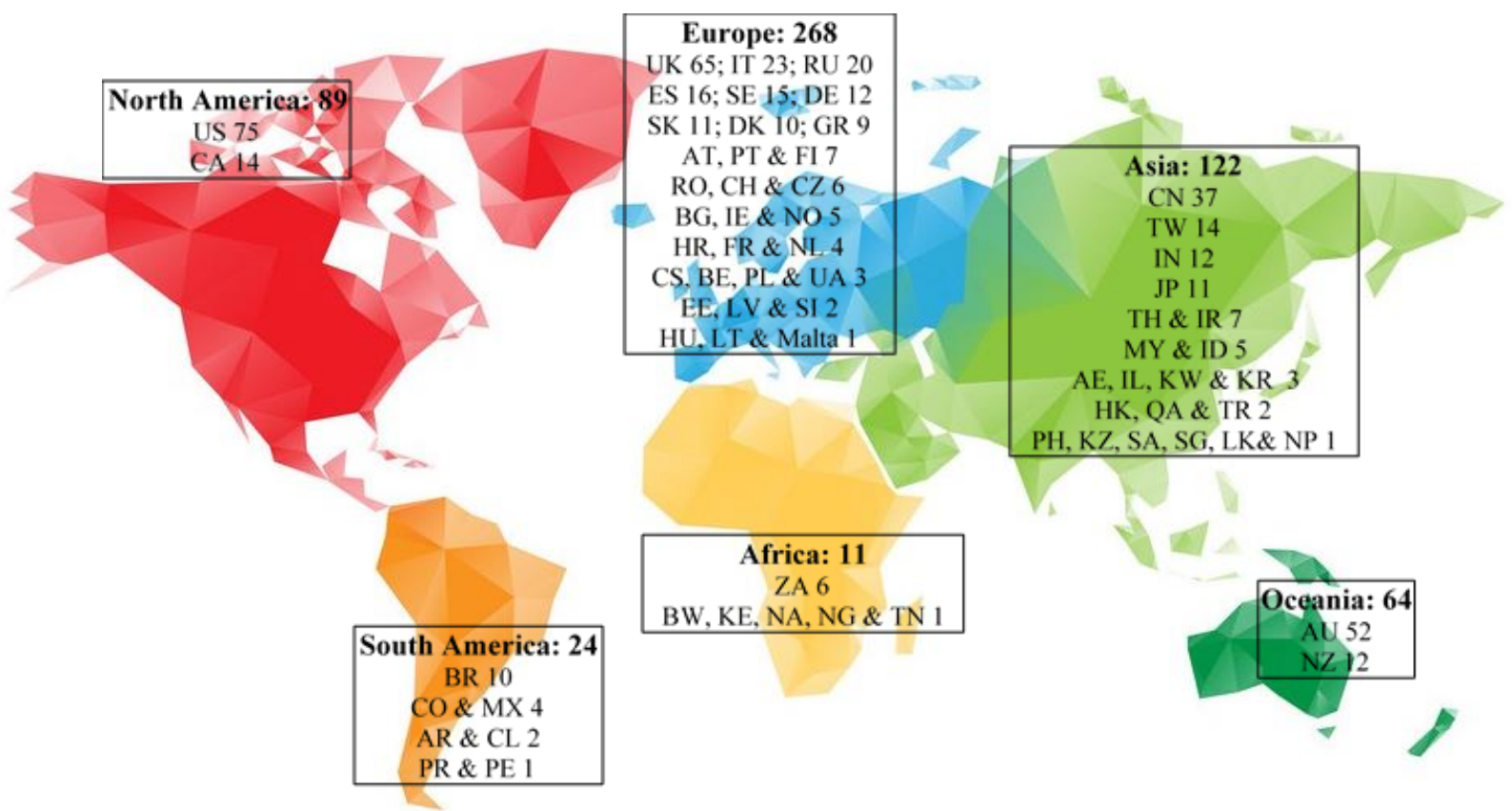

Figure 3. The spread of research across the world

Leading the publication race is the United States (75) followed by the United Kingdom (65) and Australia (52) who make up the top three contributors which collectively constitute more than $40 \%$ of all publications on Digital education in BE.

In addition, the global south countries are represented by only $19 \%$ of the selected portfolio of documents. This could be construed to mean that research on 4th IR education is a topic of less interest to the global south countries compared to global north countries. However, since the youth population in global south countries continues to grow and graduation rates in secondary education have increased dramatically in recent years, there is an intense need for improvement in their higher education (World Bank, 2011). Hence the research efforts topical to the global south countries with respect to incorporation of the 4th IR in higher education is of the essence.

\subsection{Keyword Analysis}

A keyword analysis was executed to verify the findings of the key research topics of digital technologies in EBE education. Usually scholars use slightly different keywords to indicate the same or a similar concept. Therefore, the keywords were manually examined to recognise similarities. Finally, 461 keywords and 3410 co-keywords were extracted from the 582 selected documents from the database. 
In the next step, the occurrence of a selected keyword was calculated, and the keywords according to their occurrence were ranked according to following steps:

- Step 1: MS Excel was used to develop a node table that quantified the recurring keywords in selected documents and an edge matrix was developed to quantify the occurrence of co-keywords appearing in one article.

- Step 2: The node table and edge matrix were imported into the Gephi software to establish a visual image of the resultant keyword network.

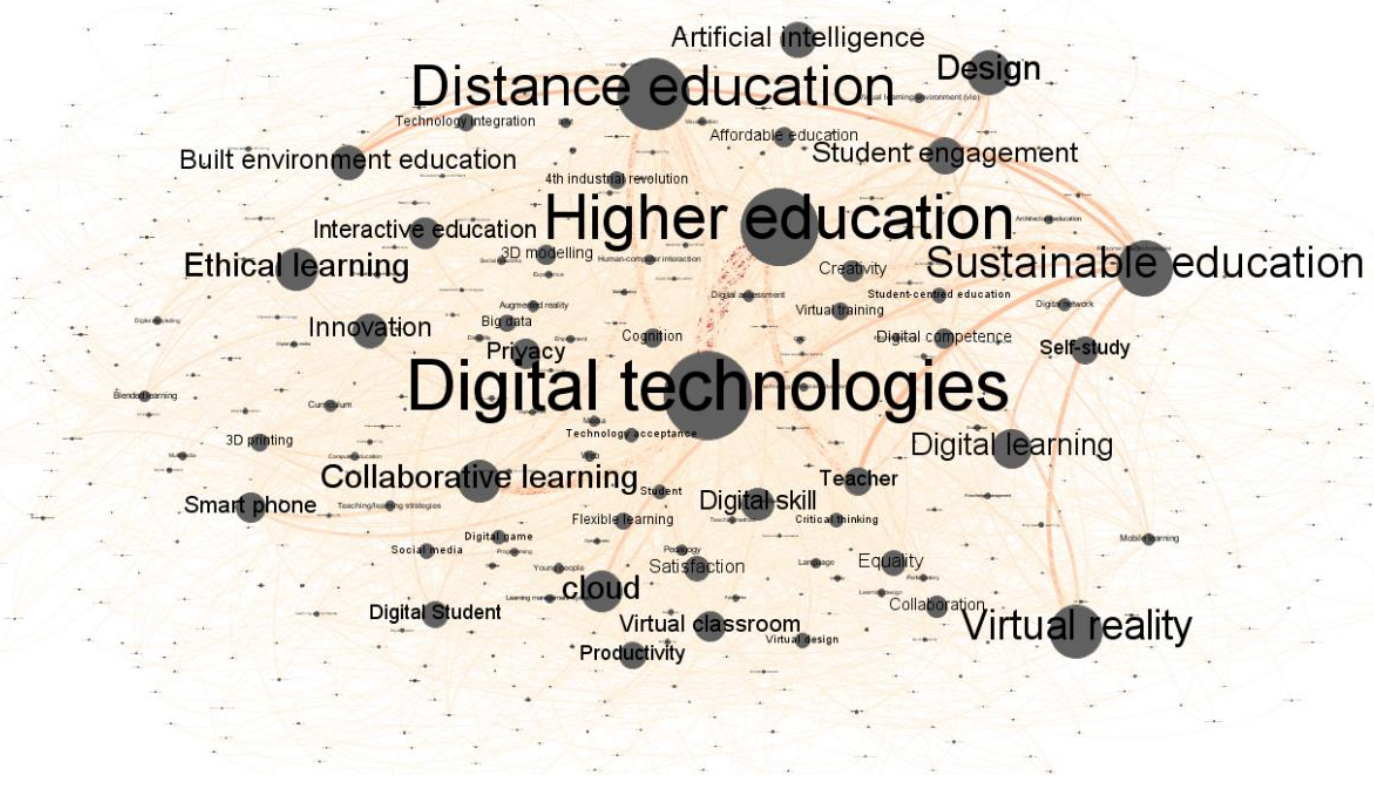

Figure 4. Keyword network

In Figure 4, each node represents a keyword, and its size reflects the number of recurring keywords in the sample size of documents. Digital technologies, Higher education, Distance education, Sustainable education and Virtual reality are the top five keywords used by most of the research on incorporating 4th IR in BE education. The links in Figure 4 between nodes denote the interconnection among keywords, and the thickness of each link denotes the interconnection strength (i.e. the number of times the two keywords were found together in a publication). Digital technologies and Higher education (46), Digital technologies and Collaborative learning (22), Digital technologies and Sustainable education (20), Digital technologies and Teacher (15), and Teacher and Higher education (15) are the pair of keywords with the strongest interconnection respectively.

\subsection{Keyword Clustering Analysis}

The Giant Component analysis is applied on the initial network, and the six nodes that were found not to be connected to the main network were eliminated, thus verifying that more than $99 \%$ of selected keywords are interconnected to the main network and could thus be considered in the further network analysis. 
To complete the keyword clustering analysis, three highly regarded experts in fields of Engineering and Built Environment Education and Digital Technologies conglomerated the identified keywords in four clusters, namely Context, Education method, Education tools and techniques and Outcome. The four clusters were applied to the 461 nodal network resultants from the keyword mapping exercise conducted with Gephi. The composition of each cluster varies from 166 keywords in the education tool and techniques group, 146 keywords in education method group, 100 keywords in context group and 42 keywords in outcome group as shown in Figure 5 below.

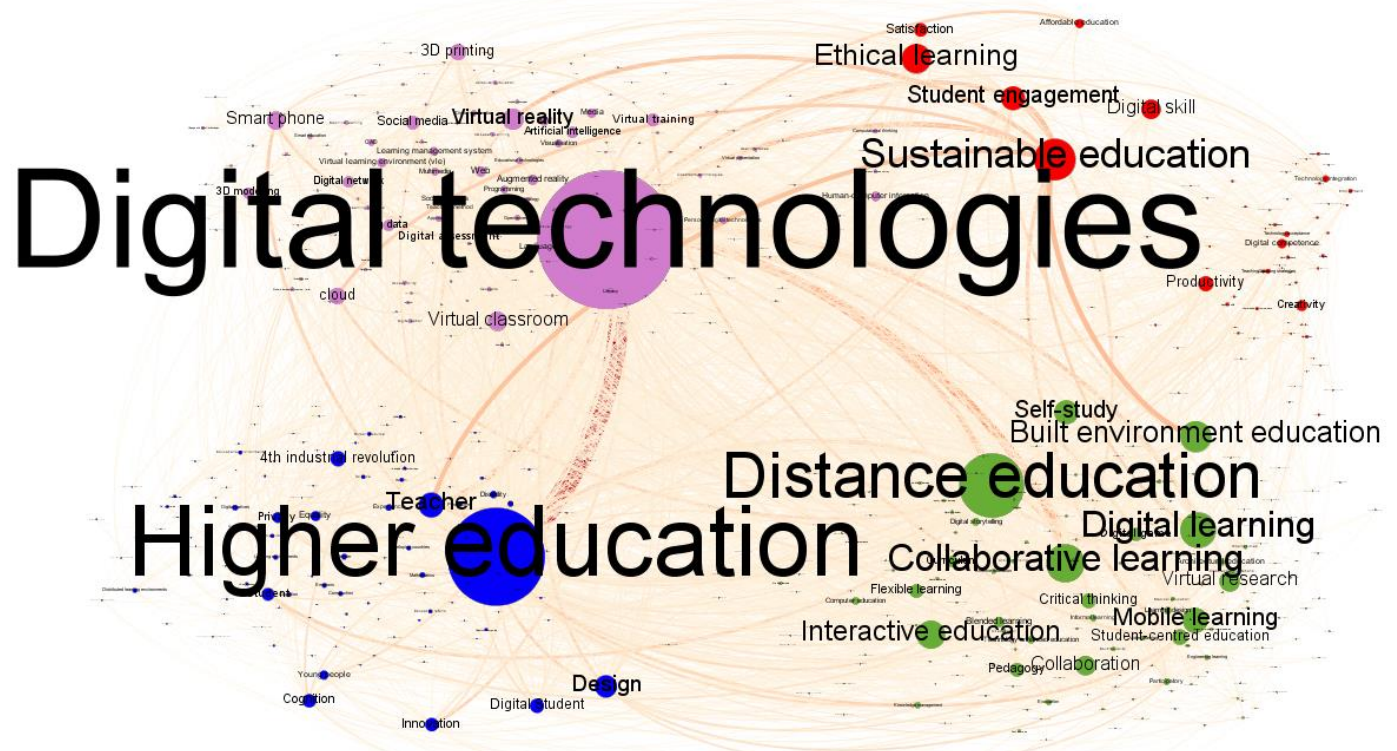

Figure 5. Clustered keyword network

Advanced statistical analysis of the four clusters of keywords were used to evaluate and validate the conglomeration of clusters as illustrated by the results from the statistical analysis listed in Table 1 below.

Table 1: Connected components and average clustering coefficient

\begin{tabular}{|l|c|c|}
\hline Group & Connected components & Average clustering coefficient \\
\hline Context & 1 & 0.647 \\
\hline Education method & 1 & 0.659 \\
\hline Education tool and technology & 1 & 0.659 \\
\hline Outcome & 1 & 0.54 \\
\hline
\end{tabular}

The connected components of all four clusters are denoted as one, which shows that all keywords in each group are interconnected. Moreover, the average clustering coefficient for all four clusters is greater than 0.5, which shows that the nodes in each cluster have strong interconnections. The connected components and average clustering coefficient of the groups validate the choice of clustering topics chosen by the experts. 


\section{DISCUSSION OF FINDINGS}

The most researched cluster of topics among the selected documents are education tools and technology with $37 \%$ of total keywords, education method with $32 \%$ of keywords, context with $22 \%$ of keywords and less topic discussed is outcome with only $9 \%$ of keywords. On the other hand, the average degree of nodes represents the importance assigned to the cluster topic by the researchers, and outcomes of digital education, education method, education tools and technology and the context of education respectively are ranked as important to incorporation into 4th IR education in BE.

Table 2: Frequency of nodes and edges

\begin{tabular}{|l|c|c|c|c|c|}
\hline Group & Nodes & Percentage & Edges & $\begin{array}{c}\text { Average degree } \\
\text { of nodes }\end{array}$ & $\begin{array}{c}\text { Rank of } \\
\text { importance }\end{array}$ \\
\hline Context & 100 & $22 \%$ & 194 & 4.476 & 4 \\
\hline Education method & 146 & $32 \%$ & 356 & 4.774 & 2 \\
\hline Education tool and technology & 166 & $37 \%$ & 417 & 4.76 & 3 \\
\hline Outcome & 42 & $9 \%$ & 59 & 6.167 & 1 \\
\hline Total & 454 & $100 \%$ & 1026 & & \\
\hline
\end{tabular}

The attribute filter was applied to the clustered keyword network to identify the key elements and evaluate the findings of the research. To determine the importance of elements of incorporating 4th IR digital in built environment education, the degree of centrality was calculated by determining which keywords within the clusters occurred in $25 \%$ or more of the documents with the results presented in Table 3 and Figure 6 below.

Table 3 shows the 31 keywords which had $25 \%$ or more recurrence in the selection of documents, therefore chosen to represent the key elements required to incorporate in 4th IR in $\mathrm{BE}$ education. There is equanimous representation among the cluster topics with $11 \mathrm{key}$ elements attributed to the educational tools and technology cluster, 10 key elements assigned to educational methods' cluster, 10 key elements associated with the outcomes' cluster and 9 key elements belonging to the context cluster as listed in Table 3 below.

Table 3: Key elements and outcomes of incorporating 4th IR in built environment education

\begin{tabular}{|l|l|c|c|}
\hline Element & Group & Degree centrality & $\begin{array}{c}\text { Relative } \\
\text { importance }\end{array}$ \\
\hline Digital technologies & Tool and Technology & 157 & 1 \\
\hline Higher education & Context & 110 & 2 \\
\hline Distance education & Method & 73 & 4 \\
\hline Sustainable education & Outcome & 57 & 5 \\
\hline Virtual reality & Tool and Technology & 54 & 6 \\
\hline Design & Context & 45 & 7 \\
\hline Ethical learning & Outcome & 43 & 7 \\
\hline Collaborative learning & Method & 43 & 8 \\
\hline cloud & Tool and Technology & 42 & 9 \\
\hline Digital learning & Method & 40 & 10 \\
\hline Student engagement & Outcome & 37 & 11 \\
\hline Artificial intelligence & Tool and Technology & 36 & 12 \\
\hline Innovation & Context & 35 & 13 \\
\hline Built environment education & Method & 35 & 14 \\
\hline Digital skill & Outcome & 33 & 15 \\
\hline Interactive education & Method & 32 & 16 \\
\hline Virtual classroom & Tool and Technology & 31 & 16 \\
\hline Privacy & Context & 30 & 17 \\
\hline Smartphone & Tool and Technology & 30 & 28 \\
\hline Teacher & Context & & \\
\hline
\end{tabular}




\begin{tabular}{|l|l|c|c|}
\hline Self-study & Method & 27 & 18 \\
\hline Productivity & Outcome & 27 & 18 \\
\hline Digital Student & Context & 26 & 20 \\
\hline Equality & Context & 25 & 20 \\
\hline Satisfaction & Outcome & 25 & 21 \\
\hline Creativity & Outcome & 22 & 21 \\
\hline Collaboration & Method & 22 & 22 \\
\hline Affordable education & Outcome & 20 & 22 \\
\hline 3D modelling & Tool and Technology & 20 & 22 \\
\hline Digital competence & Outcome & 20 & \\
\hline
\end{tabular}

As summarised in Table 3 and illustrated in Figure 6, Higher education, Design, Innovation, Privacy, Teacher, Digital Student, and Equality are the key elements within the context cluster. Distance education, Collaborative learning, Digital learning, Built environment education, Interactive education, Self-study and Collaboration are the key elements associated with the educational methods incorporating the 4th IR in BE education. Digital technologies, Virtual reality, the cloud, Artificial intelligence, Virtual classroom, Smartphone and $3 \mathrm{D}$ modelling are listed as the most common educational tools and technologies used to bring the 4th IR education into BE classrooms. Finally, Sustainable education, Ethical learning, Student engagement, Digital skill, Productivity, Satisfaction, Creativity, Affordable education and Digital competence are revealed as the main outcomes of to be expected from incorporating the 4th IR in BE education.

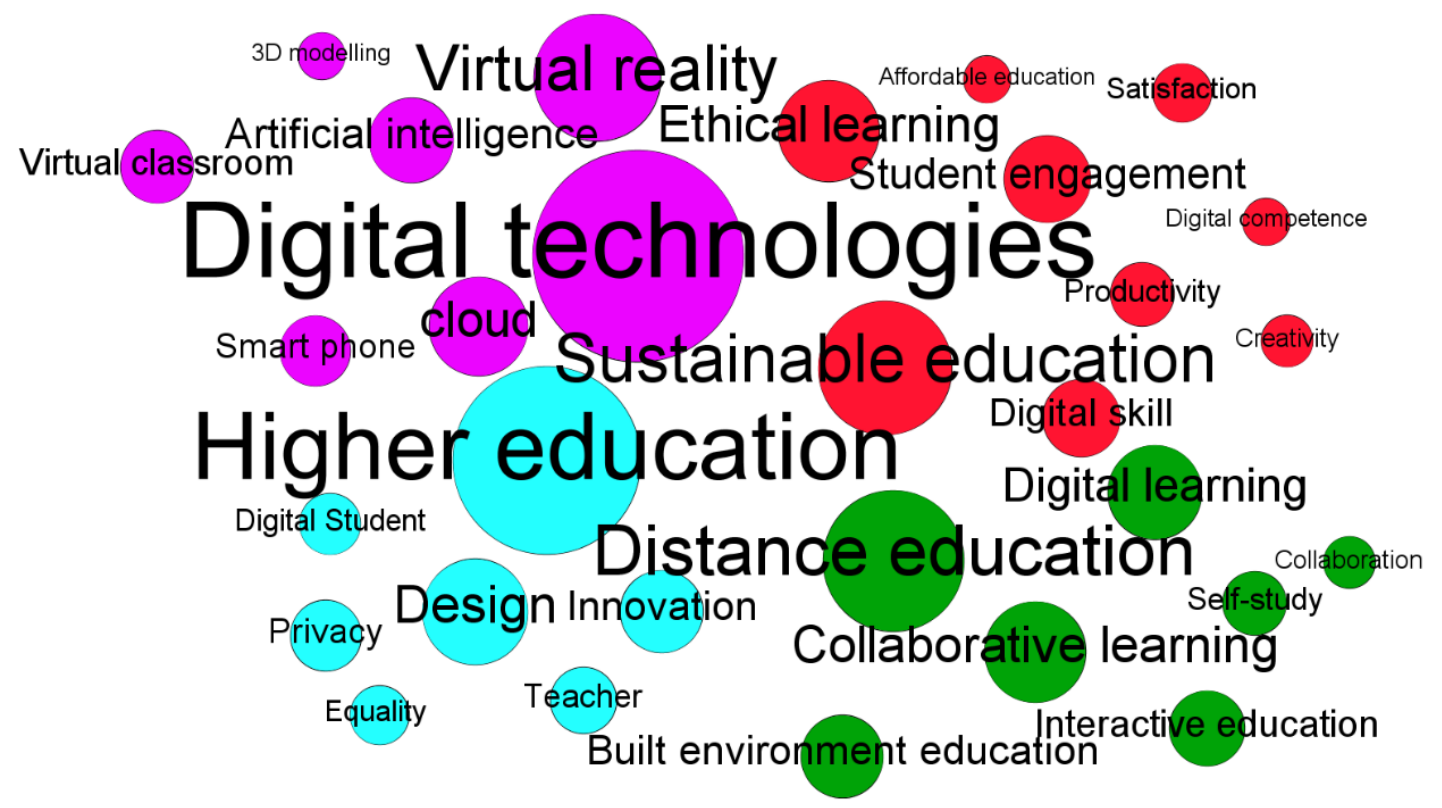

Figure 6. Key elements and outcomes of 4th IR BE education

Figure 6 clearly shows the most important elements of each group. In the context group, the higher education, teacher and design are the most common key elements. Digital technologies, virtual reality and virtual classroom are the predominant educational tools and technology. Distance education, digital learning, and collaborative learning are seen to be the most important education methods. Lastly, sustainable education, ethical learning and student engagement are considered the most important outcomes of incorporating 4th IR in BE education. 
To evaluate the interconnection between the identified key elements and outcomes, the edge filter was applied to demonstrate the links of the key element keyword network. Only the strongest interconnection between the all the key elements and the key elements associated with the outcomes' cluster were filtered and is presented in Figure 7.

Figure 7 shows a significant connection between digital technologies and higher education, which indicates the core aspects of 4th IR education. Also, the interconnection network shows the direct and indirect interconnections between the identified key elements and key elements attributed to the outcomes' cluster. Digital technologies, as the most important identified key element with the highest degree centrality and largest number of interconnections, has a direct interconnection to all key elements. Moreover, Digital technologies has a robust direct interconnection to sustainable education, ethical learning, student engagement, Digital skill, affordable education and other outcomes of 4th IR built environment education.

Figure 8 illustrates the conceptual framework that summarises the identified key elements of incorporating 4th IR in BE education and its' perceived outcomes. The proposed conceptual framework offers the opportunity for further exploration to aid the adoption of 4th IR into BE education. The 4th IR education in BE framework elucidates the process of incorporating 4th IR educational methods, tools and technologies to BE education and the outcomes of digital transformation in BE education.

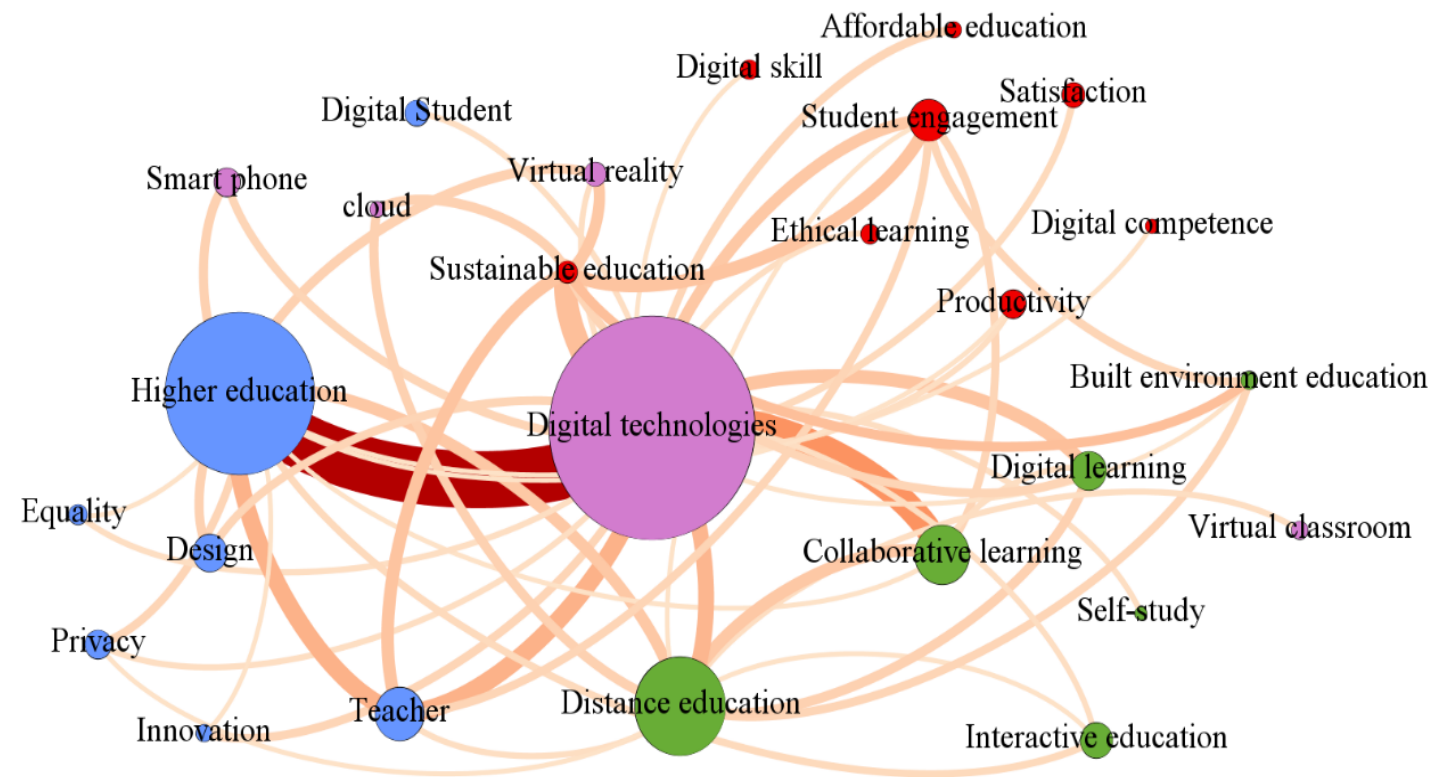

Figure 7. Interconnection network between the key elements and outcomes of 4th IR BE education 


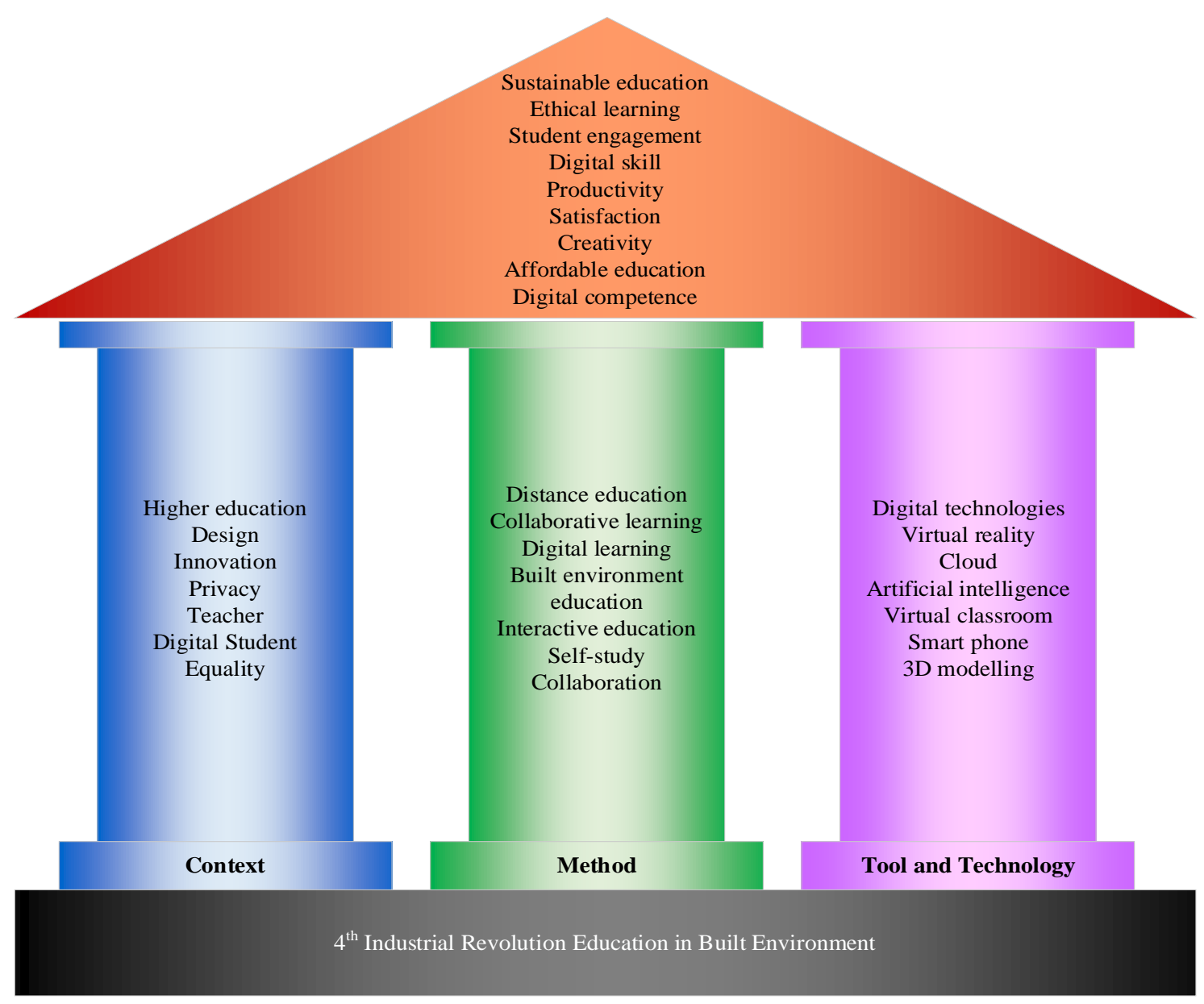

Figure 8. 4th Industrial Revolution (IR) in Built Environment (BE) education framework

\section{CONCLUSION}

The 4th Industrial Revolution is transforming the BE industry and helping to make projects safer, more efficient, and more collaborative. As a result, more significant innovation in engineering, building and construction is evident, with new materials and modern processes being deployed, and previously "impossible" projects becoming possible through innovative design and construction. Moreover, the BE industry uses a wide range of inputs from many other industries to produce its goods and services, and as a result of the BE industry also contributes indirectly to the jobs that are created across a number of sectors. As the 4th IR gathers momentum, the $\mathrm{BE}$ education fraternity requires to provide immediate and comprehensive knowledge and skills to meet the challenges that this transformation of the sector will require of them. This implies that BE education in developing world should advance swiftly in their digital technology knowledge and learn how to apply the basic 
principles of 4th IR and digitalised technologies to enhance efficiency, communication, and productivity to meet with current trends.

Digital technologies play a crucial role in reimagining how BE education can be remodelled to deliver $\mathrm{BE}$ education that enhances the learning outcomes for all students. While each university's education environment may be different, the 4th IR enables all to tailor the technological environment to their learning needs.

This study provided a holistic assessment of the key elements required to be considered when incorporating the 4th IR in BE education. The mixed bibliographic and bibliometric analysis allowed for a novel approach to be used to assess the occurrence in research documents of various educational tools and technologies, methods, context, and desired outcomes from 4th IR education as well as the relationships between these clusters of concepts.

The major findings of this study are that: research into digital and 4th IR education in $\mathrm{BE}$ has attracted much interest in the last decade with a steady increase in publication trends. The results revealed that global north countries, such as United States, United Kingdom, Australia, and China, are among the main contributors to this research field. In contrast, global south countries that are dealing with more educational problems, remain relatively inactive and should strengthen their research efforts concerning the impact of 4th IR on higher education.

This study reveals the main elements of incorporation of 4th IR in BE education, and the interconnections of co-elements, and outcomes on BE education. It emerged from the research that Education tools and technology, Method, Context and Outcome clusters, contained the highest number of features and the most significant key elements pertinent to 4th IR education that are actively researched. Furthermore, through the analysis of keyword networking, distance education, digital education, online learning and higher education appears to be the most impactful way to incorporate 4th IR in BE education. The predominant education methods investigated revealed Virtual Reality (VR), virtual classrooms and information technology to be the foremost education tools and technology. The teacher and design are considered the main contexts influencing adoption of 4th IR education, and student engagement and sustainable education are the leading outcomes. The results of the interconnection of key elements analysis revealed the strong relation of digital technology, higher education, distance education, teacher and sustainable education.

The findings of this research and the resultant conceptual framework provide a notional roadmap and practical basis on which the adoption of the 4th IR into BE education can commence. However, despite the contributions offered in this research, the findings are to be considered in light of the following limitations: choice of bibliographic databases, the search keywords attributed to published research articles. Moreover, given the objectives of the study, delving beyond the findings into aspects of "how" research into the incorporating 4th IR BE education is conducted as it is, stays outside the scope of this study. Therefore, future research may consider conducting a bibliometric analysis to identify the challenges and barriers to developing and adopting 4th IR in BE education. Indeed, the augmented understanding created by this research regarding areas neglected in the incorporation of 4th IR in BE education may cultivate academic support for more focused and profound research into the field.

\section{ACKNOWLEDGEMENT}

This research was financially supported by the Royal Academy of Engineering, UK under the Transforming Systems through Partnership (Grant No. TSP 1399). 


\section{REFERENCES}

Abdirad, H. \& Dossick, C.S. (2016). BIM curriculum design in architecture, engineering, and construction education: a systematic review. Journal of Information Technology in Construction (ITcon), Vol. 21, pg. 250-271, http://www.itcon.org/2016/17

Bai, X., He, Y., \& Kohlbacher, F. (2020). Older people’s adoption of e-learning services: a qualitative study of facilitators and barriers. Gerontology \& geriatrics education, 41(3), 291-307.

Bates T. (2016) Teaching in a Digital Age. Retrieved from http://opentextbc.ca/teachinginadigitalage/wpcontent/uploads/sites/29/2015/04/S cenario-A.mp3, Accessed: 20/06/2019

Carvalho, N., Chaim, O., Cazarini, E. \& Gerolama, M. (2018). Manufacturing in the Fourth Industrial Revolution: A Positive Prospect in Sustainable Manufacturing. Procedia Manufacturing. 21(2018), 671-678

Clevenger, C., Abdallah, M., \& Beauregard, M. (2017). Advancing construction students' sustainability competencies using online tools. In Proc., ICSC17: The Canadian Society for Civil Engineering 5th Int./12th Construction Specialty Conf. Vancouver, Canada: Univ. of British Columbia.

Costley, K. C. (2014). The Positive Effects of Technology on Teaching and Student Learning. Online Submission.

Crossan, M. M., \& Apaydin, M. (2010). A multi-dimensional framework of organisational innovation: A systematic review of the literature. Journal of management studies, 47(6), 1154-1191.

Desjardins, F., \& Bullock, S. (2019). Professional Development Learning Environments (PDLEs) embedded in a Collaborative Online Learning Environment (COLE): Moving towards a new conception of online professional learning. Education and Information Technologies, 24(2), 1863-1900.

Dombrowski, U., \& Wagner, T. (2014). Mental strain as field of action in the 4th industrial revolution. Procedia Cirp, 17(1), 100-105.

Dunleavy M. \& Dede C. (2014). Augmented Reality Teaching and Learning. In: Spector J., Merrill M., Elen J., Bishop M. (eds) Handbook of Research on Educational Communications and Technology. Springer, New York, NY

Foroughi Sabzevar, M., Gheisari, M., \& Lo, L. J. (2020). Improving Access to Design Information of Paper-Based Floor Plans Using Augmented Reality. International Journal of Construction Education and Research, 1-21.

Haigh, R. and Amaratunga, D. (2010), "An integrative review of the built environment discipline's role in the development of society's resilience to disasters", International Journal of Disaster Resilience in the Built Environment, Vol. 1 No. 1, pp. 11-24.

Han, I. (2020). Immersive virtual field trips in education: A mixed-methods study on elementary students' presence and perceived learning. British Journal of Educational Technology, 51(2), 420-435.

Mazumdar, S., Learnihan, V., Cochrane, T., \& Davey, R. (2018). The built environment and social capital: A systematic review. Environment and Behavior, 50(2), 119-158.

Hernandez-de-Menendez, M \& Morales-Menendez, R. (2019). Technological innovations and practices in engineering education: a review. International Journal on Interactive Design and Manufacturing (IJIDeM) Vol 13(2) 713-728

Hourani, H., \& Abdallah, M. (2018). Cloud Computing: Legal and Security Issues. In 2018 8 th International Conference on Computer Science and Information Technology (CSIT) (pp. 13-16). IEEE.

Hwang, G. (2019). Challenges for innovative HRD in era of the 4th industrial revolution. Asian Journal of Innovation and Policy, 8(2), 288-301.

Jacobs, E. (2015). The status quo of green-building education in South Africa. Acta Structilia: Journal for the Physical and Development Sciences 22(2): 110-133. 
Jin, R., Yang, T., Piroozfar, P., Kang, B. G., Wanatowski, D., Hancock, C. M., \& Tang, L. (2018). Project-based pedagogy in interdisciplinary building design adopting BIM. Engineering, Construction and Architectural Management.

Kamaruzaman, M. F., Hamid, R., Mutalib, A. A., \& Rasul, M. S. (2019). Comparison of Engineering Skills with IR 4.0 Skills. International Journal of Online and Biomedical Engineering (iJOE), 15(10), 15-28.

Khan, M. T., \& Khan, N. A. (2018). ATTRIBUTES OF'DIFFUSION OF INNOVATIONS'OF BUSINESS PRODUCTS. International Journal of Information, Business and Management, 10(3), 1-14.

Kozma, R.B. (2003) Technology, Innovation and Educational Change: A Global Perspective. International Society for Technology in Education.

Mihindu, S., \& Arayici, Y. (2008, July). Digital construction through BIM systems will drive the re-engineering of construction business practices. In 2008 international conference visualisation (pp. 29-34). IEEE.

Moghayedi, A. (2019). Modelling uncertainty of cost and time in infrastructure projects (Doctoral dissertation, Engineering and the Built Environment).

Newman, D. (2017). Top 6 Digital Transformation Trends in Education. Retreived from: https://www.forbes.com/sites/danielnewman/2017/07/18/top-6-digitaltransformation-trends-in-education/\#5aeb2edb2a9a. Assessed: 23/06/2019

Parn, E. A., \& Edwards, D. (2019). Cyber threats confronting the digital built environment. Engineering, Construction and Architectural Management.

Periera, A.C. \& Romero, F. (2017). A Review of the Meanings and the Implications of the Industry 4.0 Concept. Procedia Manufacturing. 13 (2017), 1206-1214

Phillips, M. (2017). How virtual reality technology is changing the way students learn. Retreived from: http://theconversation.com/how-virtual-reality-technology-ischanging-the-way-students-learn-63271. Assessed:23/06/2019

Rojas, E.M., and Mukherjee, A. (2005). General-Purpose Situational Simulation Environment for Construction Education." Journal of Construction Engineering and Management, ASCE, Vol. 131(3), pp 319-329.

Schilling, M. A., \& Shankar, R. (2019). Strategic management of technological innovation. McGraw-Hill Education.

Schmidt, R., Möhring, M., Härting, R. C., Reichstein, C., Neumaier, P., \& Jozinović, P. (2015). Industry 4.0-potentials for creating smart products: empirical research results. In International Conference on Business Information Systems (pp. 16-27). Springer, Cham. Schrock, K. (2014). Kathy Schrock's guide to everything. Retrieved from http://www.schrockguide.net/samr.html Accessed: 20/06/2019

Shafii, F., Ali, Z.A. \& Othman, M.Z. (2006). Achieving sustainable construction in the developing countries of Southeast Asia. In: Proceedings of the 6th Asia-Pacific Structural Engineering and Construction Conference (APSEC 2006), 5-6 September 2006, Kuala Lumpur, Malaysia. Skudai: Universiti Teknologi Malaysia, pp. C29-44.

Shvets, G. A., \& Nedviga, E. S. (2019). Computer-aided design software for education in Building Engineering. AlfaBuild, (4), 34-53.

Smith, J. and Hu, R. (2013) 'Rethinking teacher education: synchronizing eastern and western views of teaching and learning to promote 21 st century skills and global perspectives', Education Research and Perspectives (Online), Vol. 40, pp.86-108, Retrieved from http.//ezproxy.cul.columbia.edu/login?url=http.//search.proquest.com.ezproxy.cul.c olumbia.ed u/docview/1462385468? accountid $=10226$

Solnosky, R., Parfitt, M. K., \& Holland, R. (2015). Delivery methods for a multi-disciplinary architectural engineering capstone design course. Architectural Engineering and Design Management, 11(4), 305-324. 
Taguma, M., Feron, E., \& Meow Hwee, L. I. M. (2018). Future of Education and Skills 2030: Conceptual Learning Framework.

Wadhera, M. (2016) 'The information age is over; welcome to the experience age', Tech Crunch, May, Vol. 9, Retrieved from https.//techcrunch.com/2016/05/09/theinformation-age-is-overwelcome-to-the-experience-age/

Walden, N. (2017). Four key areas for digital transformation in procurement. https://www.supplychaindigital.com/procurement/four-key-areas-digitaltransformation-procurement. Assessed: 14/06/20219

Windapo, A., \& Moghayedi, A. (2019). The Use of Geographic Information Systems (GIS) in Understanding Building Material Price Dispersion in South Africa. Innovative Production and Construction: Transforming Construction Through Emerging Technologies, 225.

Windapo, A. O., \& Moghayedi, A. (2020). Adoption of smart technologies and circular economy performance of buildings. Built Environment Project and Asset Management.

World Bank. (2011). Learning for all: Investing in people's knowledge and skills to promote development. World Bank Group Education Strategy 2020.

Whyte, J. (2017). The Importance of Continuous Research. Institution of Civil Engineers (ICE) Imperial College London. 